\title{
Degradation of Toxic Dye Using Phytomediated Copper Nanoparticles and Its Free-Radical Scavenging Potential and Antimicrobial Activity against Environmental Pathogens
}

\author{
S. Rajeshkumar $\mathbb{D}^{1},{ }^{1}$ M. Vanaja, ${ }^{2}$ and Arunachalam Kalirajan $\mathbb{D}^{3}$ \\ ${ }^{1}$ Nanobiomedicine Lab, Department of Pharmacology, Saveetha Dental College and Hospitals, Saveetha University, SIMATS, \\ Chennai-600077, Tamil Nadu, India \\ ${ }^{2}$ SPKCES, Manonmaniam Sundaranar University, Alwarkurichi-627410, Tamil Nadu, India \\ ${ }^{3}$ Department of Science and Mathematics, School of Science, Engineering and Technology, Mulungushi University, \\ Kabwe 80415, Zambia \\ Correspondence should be addressed to Arunachalam Kalirajan; akalirajan@mu.edu.zm
}

Received 7 October 2021; Accepted 19 November 2021; Published 3 December 2021

Academic Editor: Kumaran S

Copyright (c) 2021 S. Rajeshkumar et al. This is an open access article distributed under the Creative Commons Attribution License, which permits unrestricted use, distribution, and reproduction in any medium, provided the original work is properly cited.

\begin{abstract}
The present investigation deals with the green synthesis of copper nanoparticles in an ecofriendly manner using leaf extract of Andrographis paniculata. Green-synthesized copper nanoparticles were studied for their antibacterial, antioxidant, and catalytic activity. The leaves were powdered and extracted with water and added to copper sulphate solution. The reduction of copper ions to nanoparticles was preliminarily identified by the color change of the reaction mixture. The synthesized nanoparticle was characterized by using a UV-Vis Spectrophotometer at a different wavelength with different time intervals. Functional groups available on the surface of the nanoparticle were identified by Fourier transform infrared spectroscopy (FTIR). Surface roughness was characterized by atomic force microscopy (AFM). X-ray diffraction (XRD) analysis showed six distinct intense peaks indicating the crystalline nature of synthesized copper nanoparticles (CuNPs). A scanning electron microscope (SEM) demonstrated polydispersed nanoparticles formed in the reaction process. The antibacterial activity of the nanoparticles was evaluated by an agar well diffusion assay against pathogenic bacteria. The antioxidant activity showed the excellent reduction of DPPH free radicals by nanoparticles. These results confirmed that copper nanoparticles serve as an alternative therapeutic agent over conventional drugs. Moreover, copper nanoparticles were also used to study the effect on the dye degradation process of methyl red and eosin dyes. Copper nanoparticles effectively remove the dyes with high efficiency up to $92 \%$ and $95 \%$ of methyl red and eosin dye, respectively.
\end{abstract}

\section{Introduction}

Nanotechnology creates nanomaterials with desired properties and small size falling into the nanometer scale [1]. The small-sized nanoparticles have a high surface area compared to bulk materials. Development of bioinspired nanoparticles is an immensely growing field in modern technology [2]. Various methods are available for fabrication of bioinspired nanoparticles such as physical, chemical, and biological methods. Moreover, the biological method includes using bacteria [3], fungi [4], virus and algae [5], and yeast and plants [6]. Microbe-mediated synthesis required frequent microbial cell culture maintenance and adequate handling experiences. But, among the methods, plant-derived nanoparticles are highly acceptable and preferable due to their environment friendliness, no usage of toxic chemicals, eliminating culture maintenance process, and no need of physical and chemical parameters [7]. Phytomediated synthesis of nanoparticles is based on the concept of phytoremediation of metals. Selection of plant for the nanoparticles synthesis is based on the heavymetal resistance capability [8]. 
Among the noble metals, copper is abundantly available in the earth crust and exists in low stable metallic form. Copper is a crucial trace element in the biological system. Copper is extensively used because of high costs other noble metals compared to copper. Currently, copper nanoparticles have been attaining great attention due to their catalytic, optical, and electrical properties [9]. Therefore, copper is mostly preferred for the synthesis process because of low cost and high conductivity. Copper nanoparticles are widely used as antimicrobial, antioxidant, anticancer, anti-inflammatory, and antihepatotoxic agents. Currently, copper nanoparticles are used as an alternative feed additive in animal feed, especially poultry diet [10].

Andrographis paniculata (king of bitters) belongs to the family Acanthaceae, widely grown in Asian countries. In ancient medicinal system, this herb was used in therapeutic formulations to treat liver disorders. This plant has andrographolide, a bitter taste-giving major compound, and also has diterpene lactone [11] which is responsible for its pharmacological activities [12]. A. paniculata has various beneficial activities such as antioxidant [13], anticancer [14], hepatoprotective [15], antimicrobial [16], antidiabetic [17], antifertility [18], and antimalarial activity [19].

Methyl red is an azo dye with the molecular formula $\mathrm{C}_{15} \mathrm{H}_{15} \mathrm{~N}_{3} \mathrm{O}_{2}$. Typically, methyl red dye is used in various industries such as textile, pharmaceutical, cosmetics, and tannery. The effluent releases from the industries are very toxic to the human beings.

The molecular formula of eosin is $\mathrm{C}_{20} \mathrm{H}_{6} \mathrm{Br}_{4} \mathrm{Na}_{2} \mathrm{O}_{5}$. Eosin is also commonly named as acid red 87 , eosin yellowish, and so on. It is used for diverse purpose in the industries such as pharmaceutical, cosmetics, and textile. It is also used for tissue stain as well as counter stain. The existence of the hazardous dye in the terrestrial and aquatic environment leads to harmful health effects to the human beings such as cancer, tumor, and skin diseases.

In previous decades, physical and chemical methods were predominantly used for the degradation of dye. However, they have many draw backs. In order to avoid those issues, nowadays, biological methods are widely used for the degradation of hazardous dyes. Nowadays, nanoparticles are greatly receiving attention in degrading toxic dyes due to their large-surface-area properties [20]. In this study, copper nanoparticle was prepared by the simple green method and characterized. Synthesized nanoparticle was applied in various targeted applications such as antimicrobial, antioxidant, and catalytic activity.

\section{Materials and Methods}

2.1. Preparation of Plant Extract. The leaves of A. paniculata were collected from Vellore district. The freshly collected leaves were washed thoroughly with distilled water thrice and shade-dried for a few days at room temperature, and then, a fine powder was obtained using a blender. In this study, $5 \mathrm{~g}$ of plant powder was accurately weighed and added into a $250 \mathrm{~mL}$ conical flask containing $100 \mathrm{ml}$ of double distilled water. The mixed suspension were boiled in a microwave oven for 5 minutes followed by double filtration accomplished with Whatman No.1 filter paper, and the consequent suspension was stored at $4^{\circ} \mathrm{C}$ for the further experiments.

2.2. Green Synthesis of Copper Nanoparticles. For the biosynthesis of CuNPs, $25 \mathrm{ml}$ of aqueous leaf extract was assorted with $75 \mathrm{ml}$ of distilled water containing 10 millimolar of copper sulphate. The prepared solutions were incubated in a shaker at room temperature for $24 \mathrm{~h}$. After the incubation time, the change in the color of the solution owing to the formation of copper nanoparticles was observed by using a UV-Visible spectrophotometer.

\subsection{Characterization of Green-Synthesized Copper} Nanoparticles. Synthesis of copper nanoparticles was carried out by forming an SPR band measured in a doublebeam UV-Vis Spectrophotometer. Crystalline structure and morphology of nanoparticles were observed by X-ray diffraction and scanning electron microscope analysis, respectively. The surface roughness and topography character were evaluated by atomic force microscopy analysis. Functional groups present on the surface of the nanoparticle were characterized by Fourier transform infrared spectroscopy.

\subsection{Various Applications of Copper Nanoparticles}

2.4.1. Antibacterial Activity. Antibacterial activity of synthesized copper nanoparticles was determined by the agar well diffusion method. In this assay, about five microorganisms were used, Bacillus sp., E. coli, Klebsiella sp., S. aureus, and Proteus sp. Fresh overnight cultures of the abovementioned organisms were separately and evenly spread using a sterile cotton swab on a Muller Hinton Agar plate. About $6 \mathrm{~mm}$ diameter-sized four wells were made on the plate using gel puncture. Each well was filled with $50 \mu \mathrm{L}$ of leaf extract, $50 \mu \mathrm{L}(50 \mu \mathrm{g} / \mathrm{ml})$ of copper sulphate, $50 \mu \mathrm{L}$ $(50 \mu \mathrm{g})$ of copper nanoparticles, and $15 \mu \mathrm{L}(15 \mu \mathrm{g})$ of standard (ampicillin). Plates were incubated at $28-30^{\circ} \mathrm{C}$ for 24 hours, and the zone formation around the well was measured.

2.4.2. Antioxidant Activity (DPPH Scavenging Assay). $\mathrm{DPPH}$ radical scavenging assay was performed using green-synthesized copper nanoparticles. DPPH solution was freshly prepared by mixing $0.004 \mathrm{~g}$ of $\mathrm{DPPH}$ in $95 \%$ methanol. $2.9 \mathrm{ml}$ of DPPH solution was taken in four test tubes, and $0.1 \mathrm{ml}$ of different concentrations $(250-1000 \mu \mathrm{g})$ of nanoparticles were added in each test tube. The reaction mixture was shaken vigorously and incubated for $30 \mathrm{~min}$, and the resulting solution was measured at $517 \mathrm{~nm}$ in a UV-Vis spectrophotometer. Control was prepared containing the same concentration of standard ascorbic acid, and 95\% methanol was used as blank. The scavenging property was calculated by using the following formula: 


$$
\text { \%inhibition }=\left[\frac{\left(\mathrm{A}_{\text {cont }}-\mathrm{A}_{\text {test }}\right)}{\mathrm{A}_{\text {cont }}}\right] \times 100 \text {, }
$$

where $A_{\text {cont }}$ is the absorbance of the control reaction and $A_{\text {test }}$ is the absorbance in the presence of samples.

2.4.3. Catalytic Reduction of Dyes. In this investigation, $10 \mathrm{mg}$ of methyl red and eosin dye were prepared in 1 liter of double-distilled water in two conical flasks. From this stock solution, $100 \mathrm{~mL}$ of methyl red and eosin dye solutions were withdrawn and added into two conical flasks. $10 \mathrm{mg}$ of green-synthesized copper nanoparticles was added into each conical flask, and control was maintained without addition of nanoparticles. The reaction solution was magnetically stirred and periodically measured by taking aliquots of $3 \mathrm{~mL}$ suspension and filtered. Filtered samples were monitored using a UV-Vis spectrophotometer at the wavelength from $300 \mathrm{~nm}$ to $800 \mathrm{~nm}$.

\section{Results and Discussion}

3.1. Visual Observation and UV-Vis Spectroscopy Studies for Copper Nanoparticles. Preliminarily, synthesis of copper nanoparticles was observed by color change in the reaction mixture. Initially, the copper sulphate solution was in light blue color. Consequently, the color of the copper sulphate solution changes from light blue color to green on addition of leaf extract of A. paniculata, and eventually, dark greenish brown color was formed owing to the formation of CuNPs, as shown in Figure 1. The occurrence of the color changes in the aqueous solution is a result of the surface plasmon resonance phenomenon. The leaf extract of $A$. paniculata acts as a reducing agent as well as stabilizing agent, which reduced the copper sulphate into copper sulphide. The synthesis of copper nanoparticles was observed using UVVis spectra. The spectral readings for the concerned sample mixture were taken from 0 to 24 hours. Predominantly, the surface plasmon resonance of CuNPs exhibits the highest absorption peak at $530 \mathrm{~nm}$, as displayed in Figure 2. Similarly, in previous studies, it has been reported that the surface resonance plasmon of CuNPs is in the range of $500-600 \mathrm{~nm}$. On the other hand, it has been revealed in the range of $550-650 \mathrm{~nm}[21,22]$.

3.2. FTIR Studies of Nanoparticles. The FTIR spectral study was carried out for the green-synthesized copper nanoparticles. The analysis was accomplished to find out the phytochemical constituents present in the crude extract of A. paniculata. These biomolecules act as a stabilizing and capping agent to bind with the metals. The peaks obtained in the copper nanoparticles are shown in Figure 3. The broad band at $3250.05 \mathrm{~cm}^{-1}$ ascribed to $\mathrm{C}-\mathrm{H}$ stretching vibrations of alkynes, hydrogen-bonded $\mathrm{O}-\mathrm{H}$ stretch of phenol, and alcohols. Furthermore, it also indicates the existence of N-H stretching vibration of secondary amine and the presence of $\mathrm{N}-\mathrm{H}$ stretch of amide which is similar to the amine group. The IR band at $1730.15 \mathrm{~cm}^{-1}$ is attributed to the presence of organic compounds such as $\mathrm{C}=\mathrm{O}$ stretch of ketones, $\mathrm{C}=\mathrm{O}$ stretch of aldehydes, and $\mathrm{C}=\mathrm{O}$ stretch of esters. The band examined at $1595.13 \mathrm{~cm}^{-1}$ illustrates the corresponding aromatic compounds such as symmetrical $\mathrm{C}-\mathrm{C}=\mathrm{C}$ stretching vibration of aromatic rings, $\mathrm{N}-\mathrm{H}$ bend of primary amines and amides, and the stretching vibrations $\mathrm{N}=\mathrm{O}$ of nitro groups. The occurrence of band from $601.79-455.20 \mathrm{~cm}^{-1}$ exhibits the formation of copper nanoparticles [23]. The previous study also confirmed that the existence of band near $400-600 \mathrm{~cm}^{-1}$ indicates the formation of $\mathrm{CuO}$ [24]. The existence of phytochemicals in the crude extract of $A$. paniculata acts as a reducing and capping agent which has an ability to reduce the $\mathrm{Cu} 2+$ ion to copper nanoparticles.

3.3. AFM Studies of Nanoparticles. Atomic force microscopy was carried out to investigate about shape and features of the nanoparticles. The topography of the CuNPs was examined in the range of $2 \mu \mathrm{m}$ and $800 \mathrm{~nm}$, as shown in Figure 4 . The images show the spherical shape with doping of biomolecules on the surface of the synthesized copper nanoparticles.

3.4. XRD Studies of Nanoparticles. The X-ray diffractometer analysis was investigated to identify the crystalline nature of the synthesized copper nanoparticles (Figure 5). The diffraction peak of CuNPs exhibited at $2 \theta$ was found to be in the range of $20-40^{\circ}$ which corresponds to the planes of (100), (002), (102), (103), (006), and (103). These planes indicate the crystalline formation of zinc sulphide nanoparticles. The average particle size of CuNPs was identified using the formula of Deybe-Scherrer. For CuNPs, the average size was $68 \mathrm{~nm}$. As per the previous studies, it has been reported that the size of the copper nanoparticles ranges from 42-90 $\mathrm{nm}$ [9].

3.5. SEM Images of Nanoparticles. The SEM analysis was carried out for the green-synthesized nanoparticles and to identify the morphology structure of the particles. Figure 6 shows the needle shape morphology to the nanoparticles. SEM image described polydispersed nanoparticles, particularly rod, spherical, and cube shape of nanoparticles with agglomeration.

\subsection{Applications of Copper Nanoparticles}

3.6.1. Antibacterial Activity of Nanoparticles. In the present study, green-synthesized copper nanoparticles exhibited a predominant role against the pathogenic bacteria such as S. aureus, Bacillus sp., Proteus sp., Klebsiella sp., E. coli, and Pseudomonas sp. by the well diffusion method. Four various control groups such as plant extract, precursor, and positive control (ampicillin) were used for the inhibition of pathogens, whereas the A. paniculata-mediated copper nanoparticles and precursor exhibit an excellent antibacterial activity against the test pathogens while compared to leaf extract and ampicillin, as depicted in Figures 7 and 8. This figure shows that Pseudomonas was inhibited by all the control groups. However, the CuNPs showed the maximum antibacterial activity against Proteus sp. followed by Bacillus 


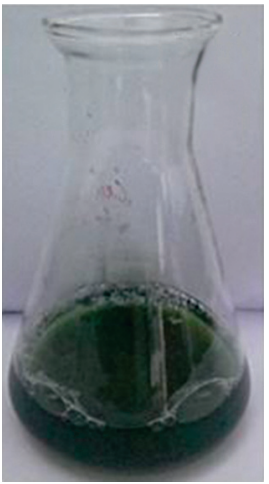

(a)

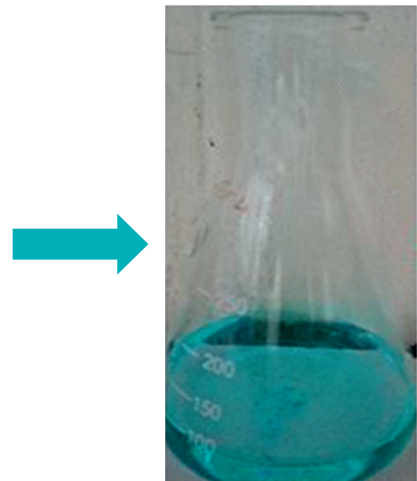

(b)

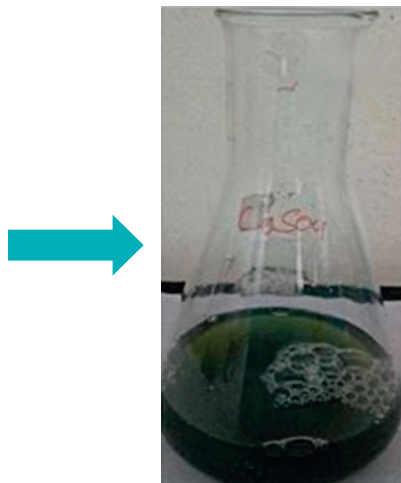

(c)

FIgURE 1: Visual observation of synthesis of copper nanoparticles. (a) Leaf extract, (b) copper sulphate, and (c) final color of CuNPs was obtained after the synthesis process of completion.

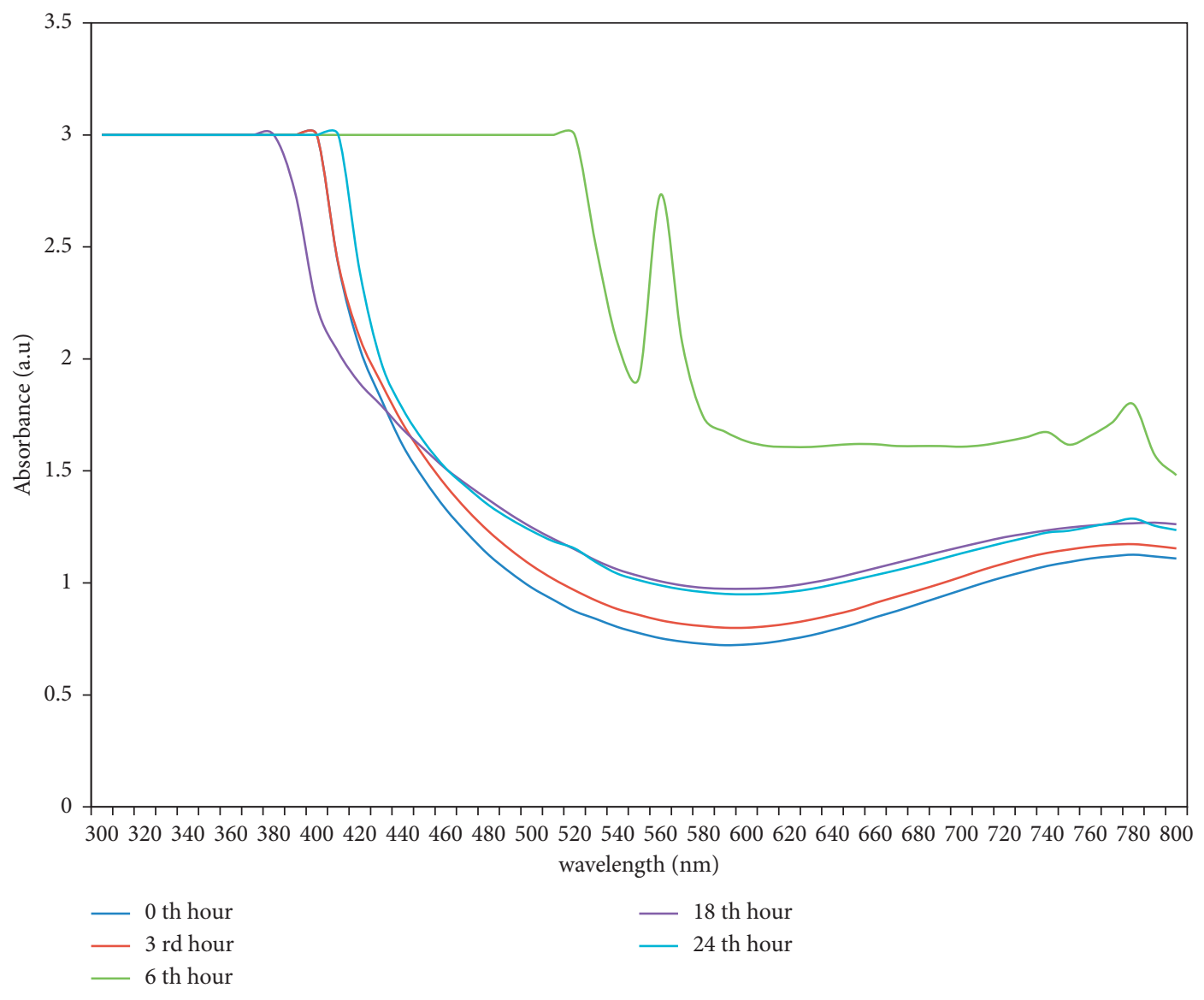

FIGURE 2: UV-Visible spectra of copper nanoparticles measured at wavelength ranges from $300 \mathrm{~nm}$ to $800 \mathrm{~nm}$.

sp., Klebsiella sp., and S. aureus, and the minimum zone of inhibition was observed against E. coli. As per the previous study, it has been stated that the bactericidal property of copper nanoparticles is typically owing to the release of copper cations $\left(\mathrm{Cu}^{+}\right.$ions) and these copper cations are adhered to the cell wall of the bacteria owing to electrostatic attraction. Furthermore, the copper metal ions not only interact on the surface of a cell membrane but also perforate into the bacteria [21].
3.6.2. Antioxidant Activity of Nanoparticles. The DPPH assay was performed to evaluate scavenging properties of the greensynthesized copper nanoparticles. The scavenging activities of CuNPs are identified owing to their ability of hydrogen donors. The result of various concentrations of CuNPs is shown in Figure 9. Ascorbic acid is used as a positive control. Results shows that both CuNPs and ascorbic acid exhibit the inhibition activity adjacent to the DPPH (1, 1-diphenyl-2-piciryl-hydrazyl) radicals. In the present study, the CuNPs exhibit the strongest 


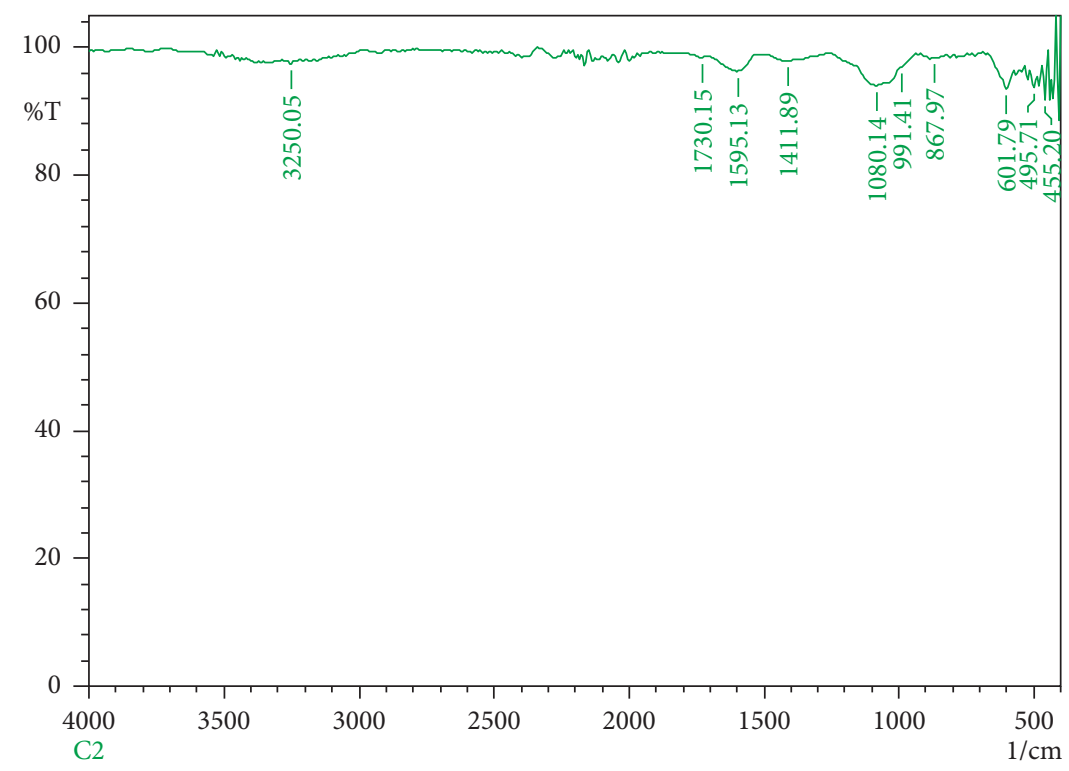

FIGURE 3: FT-IR spectrum of green-synthesized copper nanoparticles.
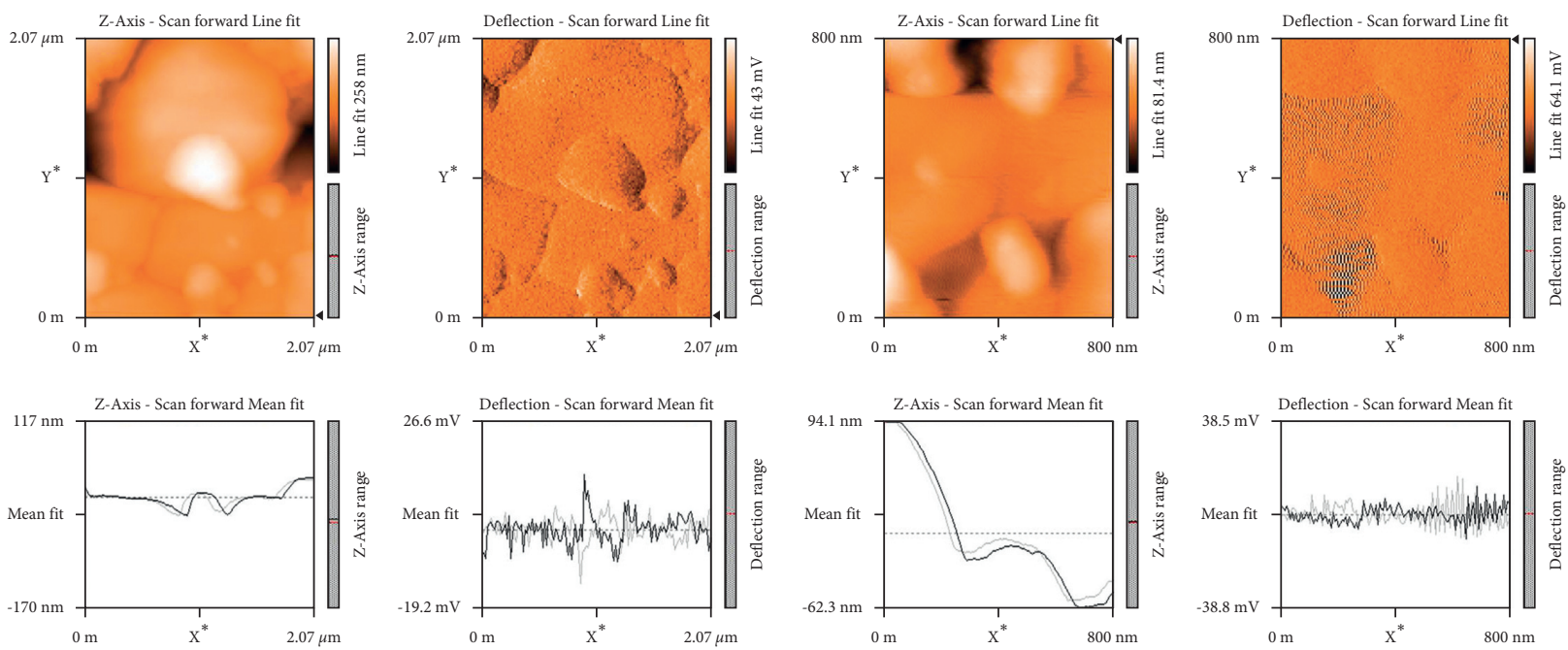

(a)
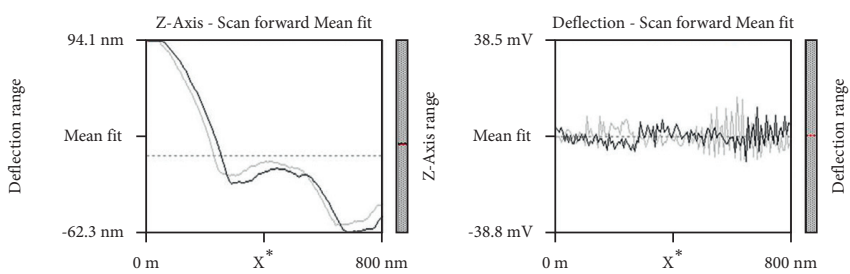

(b)

FIgURE 4: Atomic force microscopy images of copper nanoparticles. (a) $2 \mu \mathrm{m}$ and (b) $800 \mathrm{~nm}$.

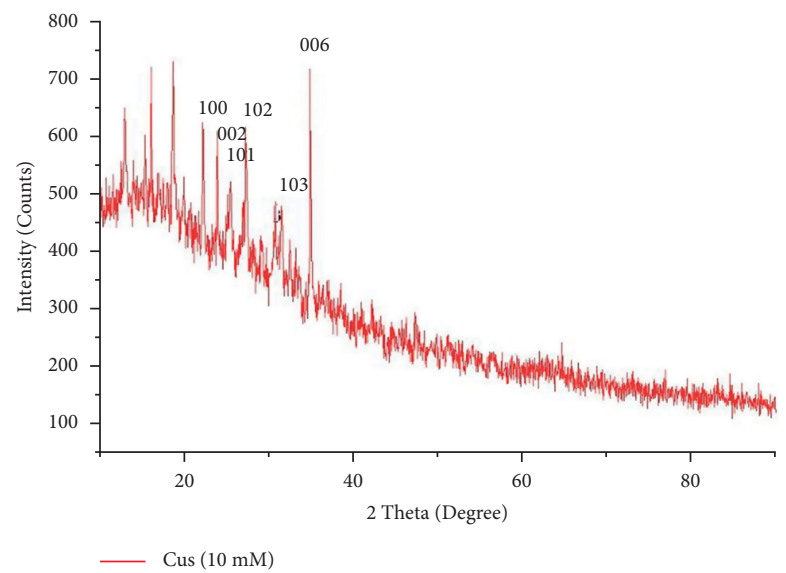

FIGURE 5: X-ray diffraction spectrum of green-synthesized copper nanoparticles shows crystalline structure. 

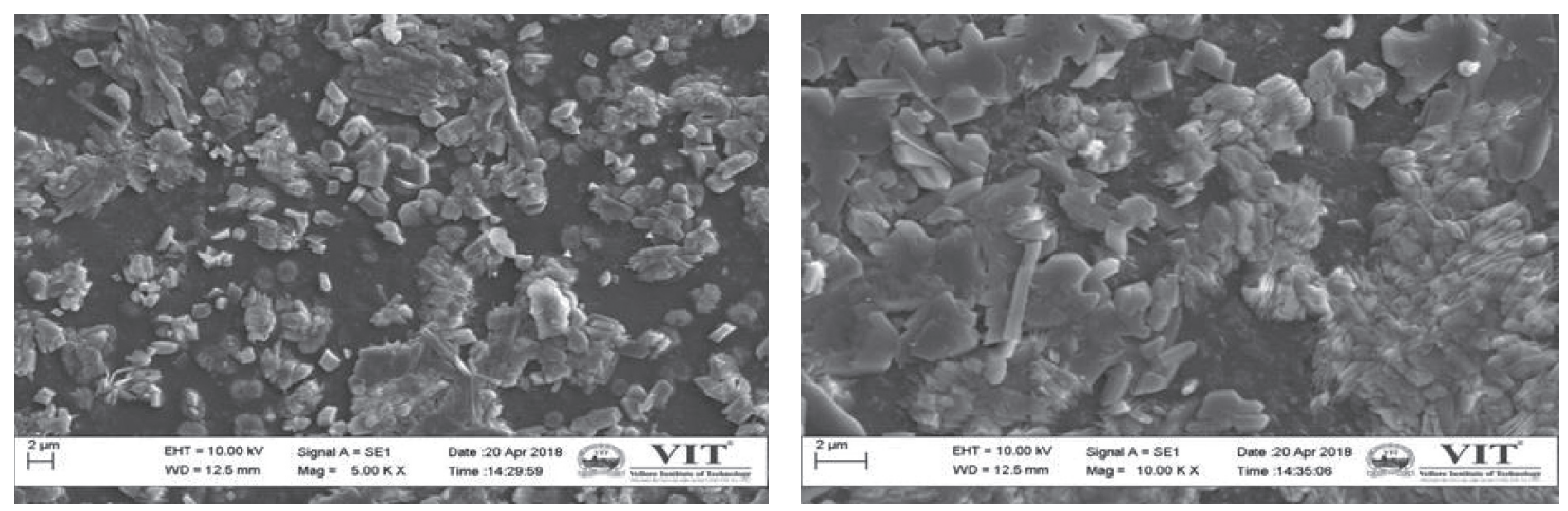

FIGURE 6: Scanning electron microscopic images of copper nanoparticles synthesized using A. paniculata.

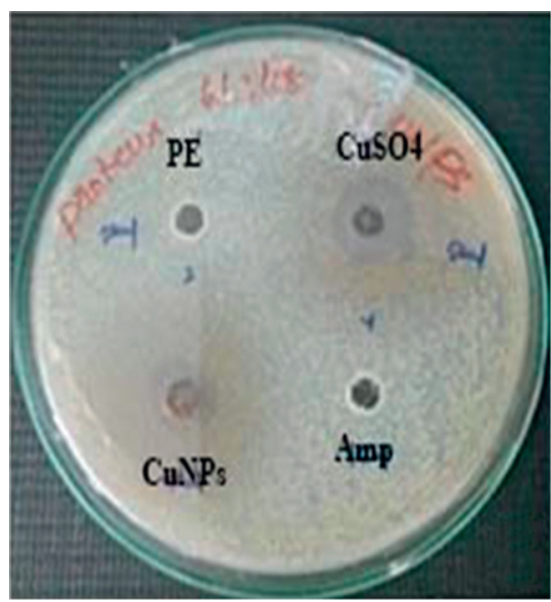

(a)

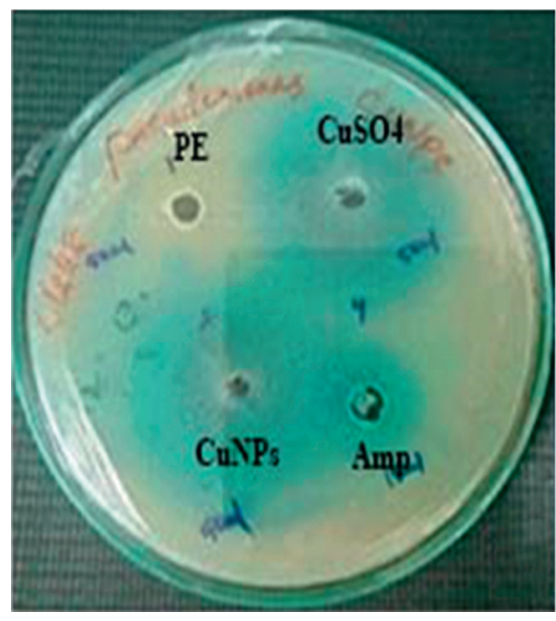

(d)

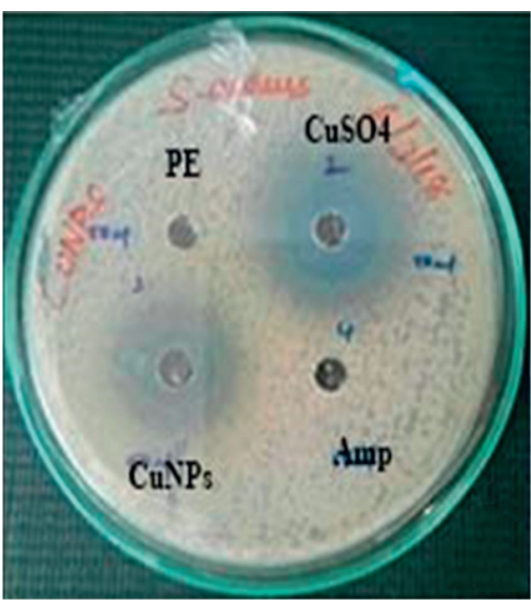

(b)

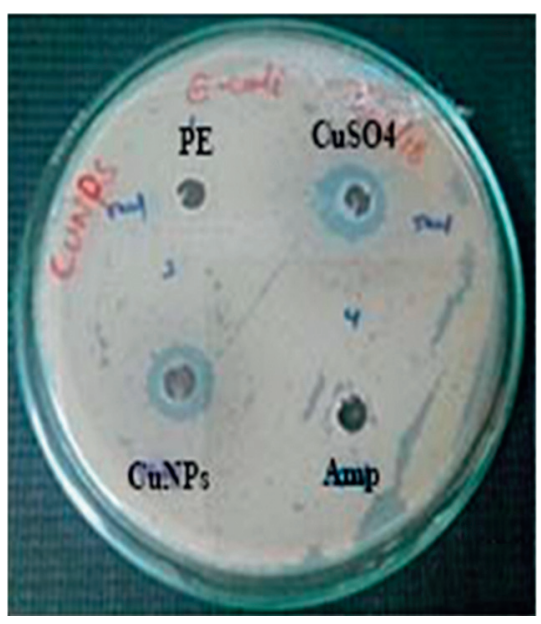

(e)

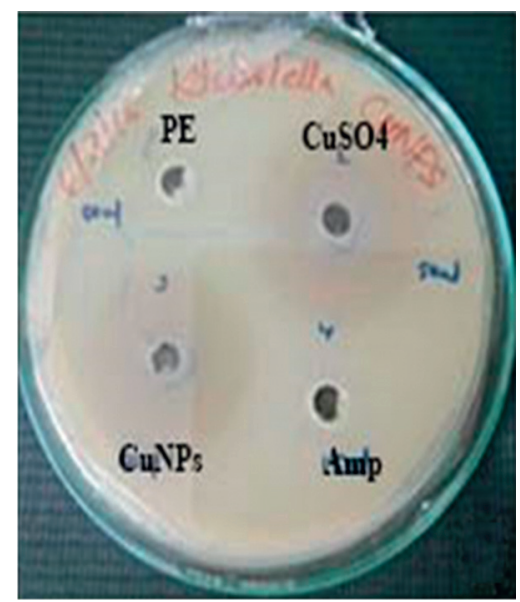

(c)

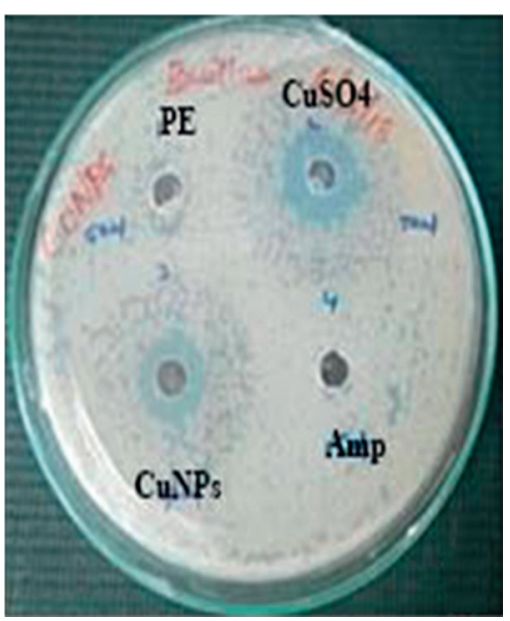

(f)

Figure 7: Antibacterial activity of copper nanoparticles. (a) Proteus, (b) S. aureus, (c) Klebsiella, (d) Pseudomonas, (e) E. coli, and (f) Bacillus sp.

inhibition of $53.04 \%$ at the concentration of $1000 \mu \mathrm{g} / \mathrm{ml}$. On the other hand, the positive control also shows the highest inhibition of $68.55 \%$ at the same concentration. Therefore, it implies that the scavenging activity of CuNPs increases while the concentration of the sample increases. The previous study also reported that the inhibitory activity increases when the concentration of the sample got increased. It also confirmed that the concerned sample exhibits higher antioxidant activity owing to the existence of phytoconstituents present in the crude extract [25]. 


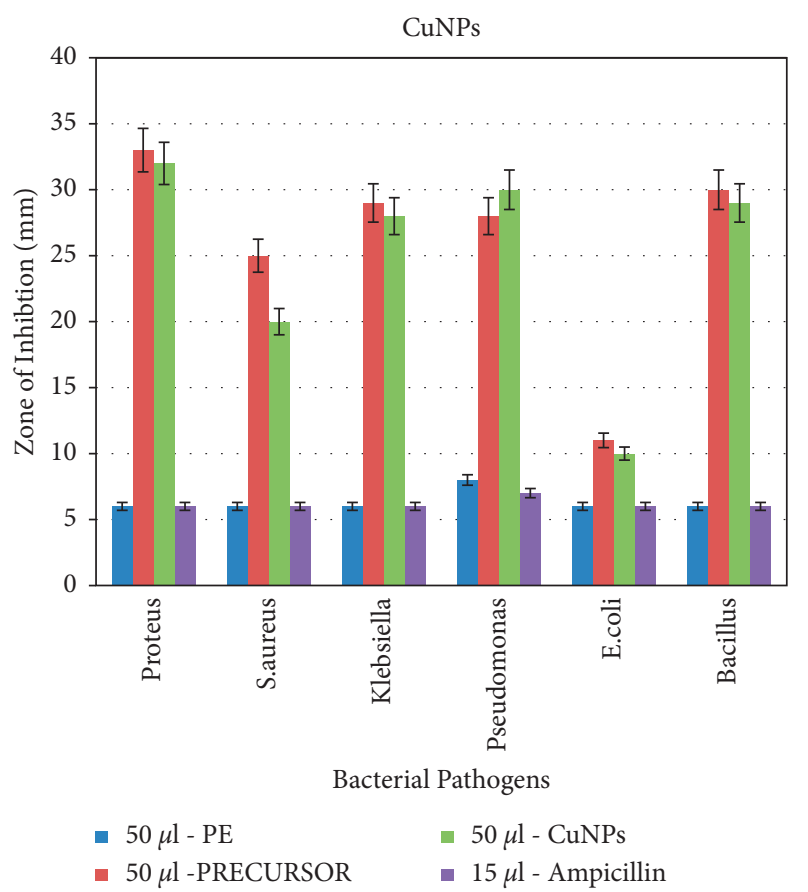

FIGURE 8: Graphical representation of the antibacterial activity of copper nanoparticles. $Y$-axis: zone of inhibition in mm, and $X$-axis: bacterial pathogens.

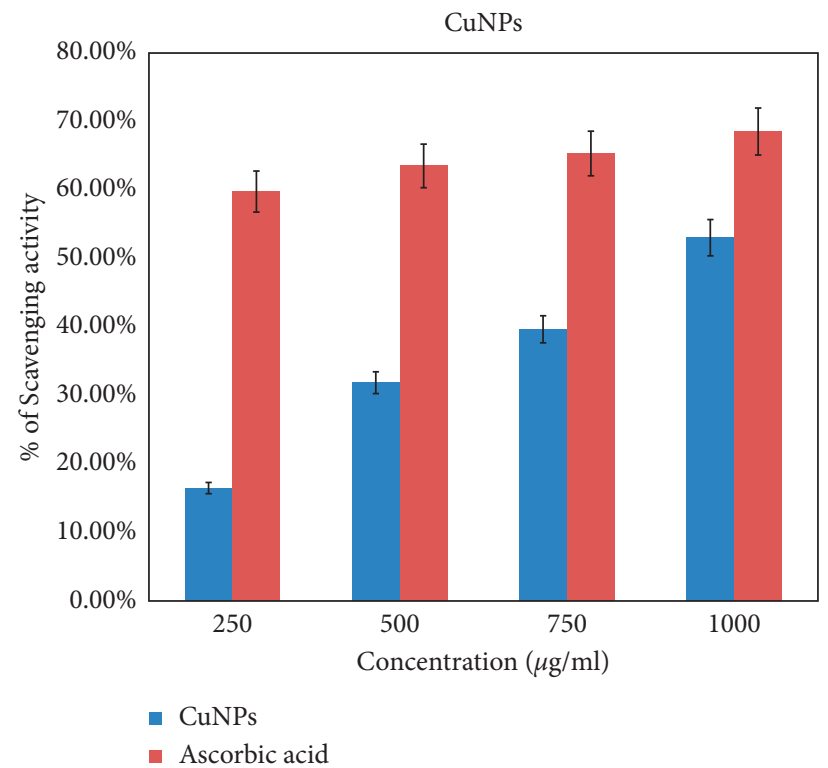

FIGURE 9: Antioxidant activity of copper nanoparticles against DPPH free radical. $Y$-axis: percentage of inhibition in mm, and $X$-axis: concentration of nanoparticles.

\subsubsection{Catalytic Degradation of Methyl Red and Eosin Dye Using Nanoparticles}

(1) Mechanism of Catalytic Degradation. As per the earlier studies, catalytic dye degradation was explained using the following mechanism. Catalytic reaction occurred on the surface of the metals present in the dye solution. Enhancing the surface area of the nanoparticles will also increase the efficiency of the catalyst used for the dye degradation. On the other hand, declining the size of the catalyst also enhances the catalytic reaction.

(2) Catalytic Degradation of Methyl Red. The catalytic activity of biosynthesized copper nanoparticles was determined by the reduction of methyl red dye at various intervals of time from $30 \mathrm{~min}-48 \mathrm{~h}$. Initially, the reduction of dye concentration in a solution by using copper nanoparticles was observed by color change. The color of the dye solution 


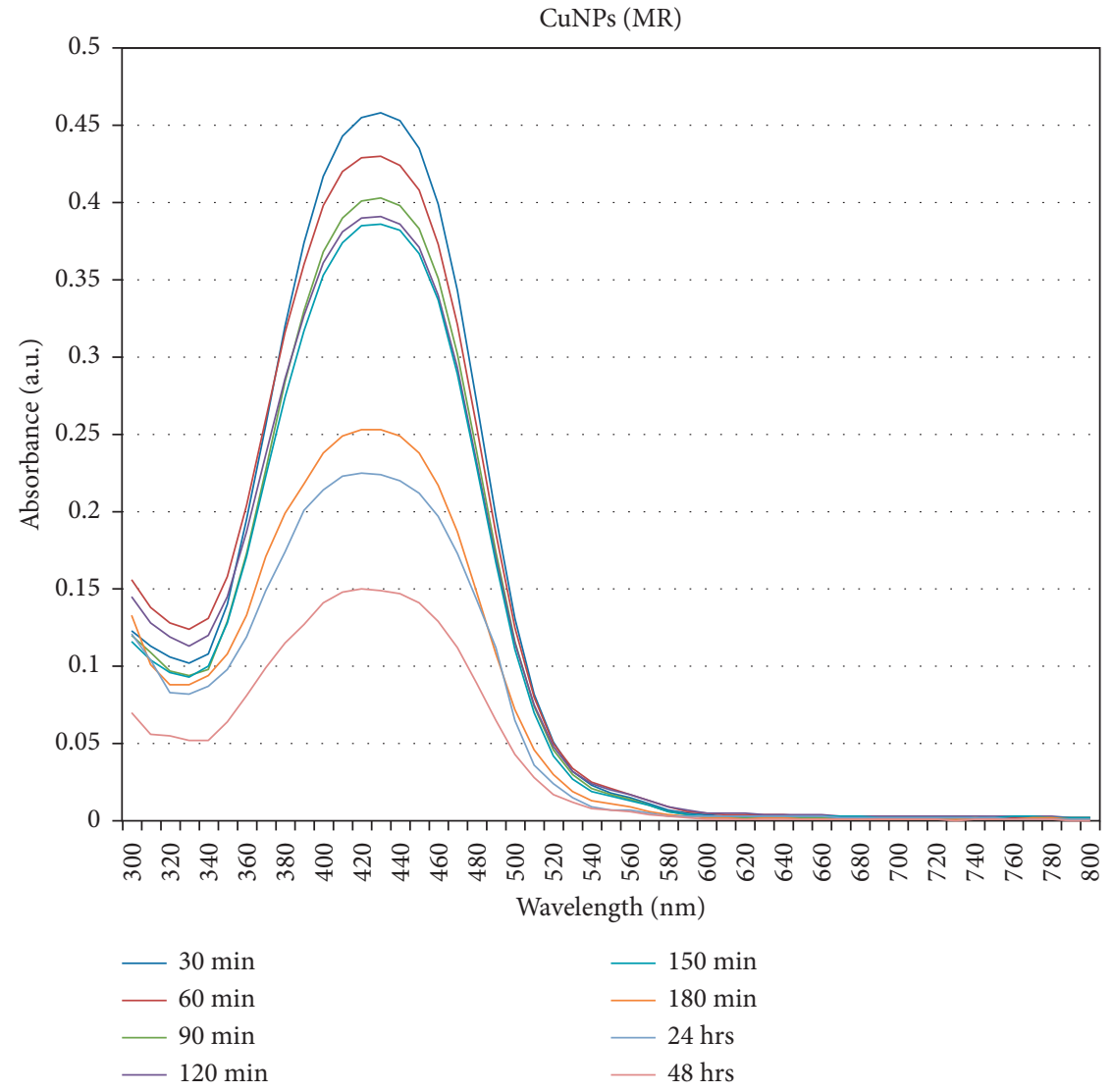

FIgURE 10: Catalytic degradation of methyl red using copper nanoparticles. $Y$-axis: absorbance, and $X$-axis: wavelength in nm.

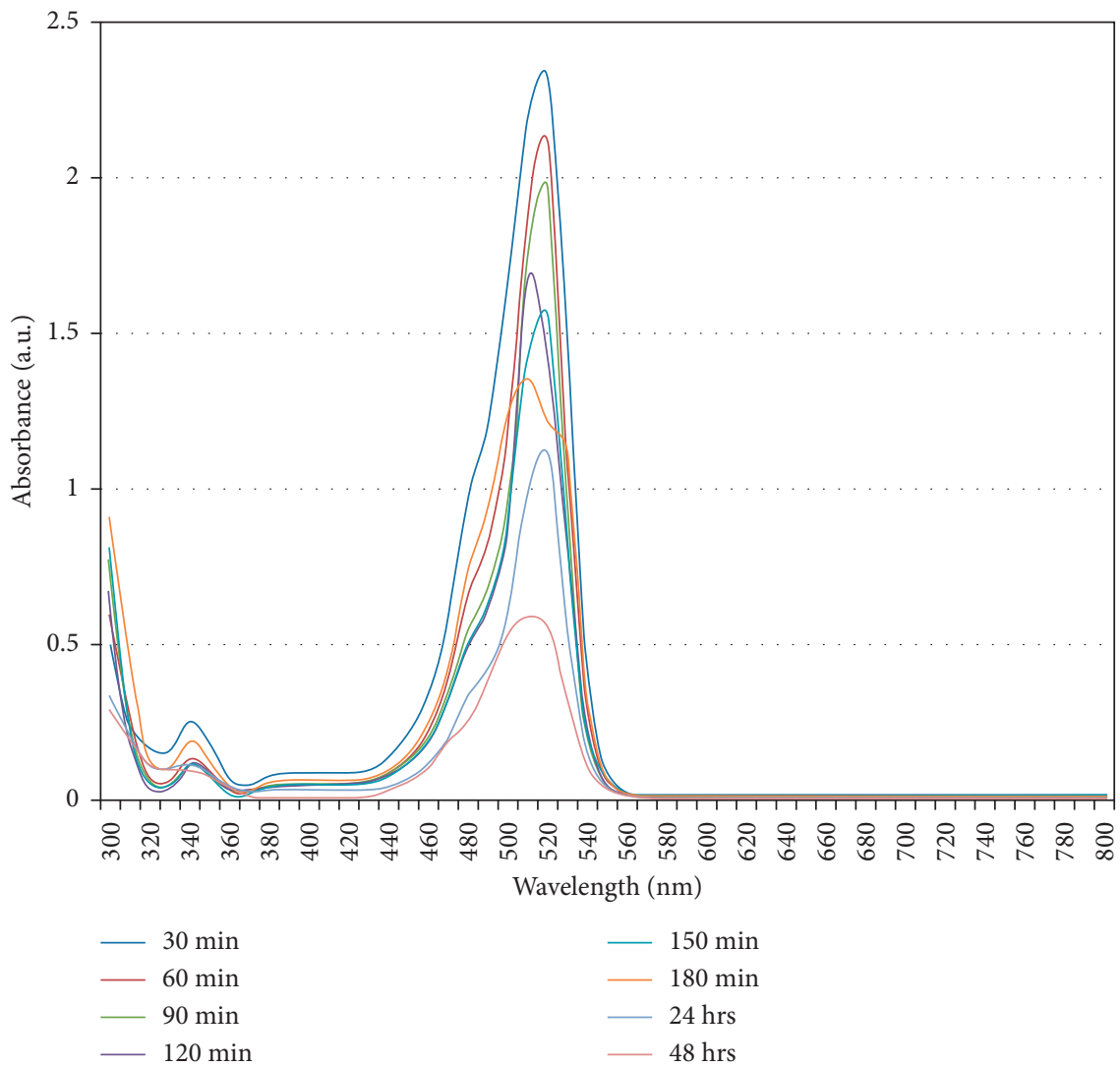

Figure 11: Catalytic degradation of eosin using copper nanoparticles. $Y$-axis: absorbance, and $X$-axis: wavelength in $\mathrm{nm}$. 
changed from red to pale white indicates the degradation or removal of dye. The progress of the dye degradation was recorded using an Ultraviolet-Visible spectrophotometer in the range of $300-800 \mathrm{~nm}$. In each interval, the maximum absorption peak was monitored at $415 \mathrm{~nm}$ for synthesized nanoparticles. Subsequently, the peak has been decreased gradually with the increase of time, which reveals the degradation of methyl red through the catalytic activity of the synthesized copper nanoparticles. The previous study also supported the result of the current study. However, in the former study, they used AgNPs as a photocatalyst for the degradation of methyl red dye [26]. Figure 10 shows that the peak at the time interval of $48 \mathrm{hrs}$ was gradually declined when compared to the other time intervals. From this, it has been revealed that a green-synthesized copper nanoparticle has an ability to degrade the methyl red dye.

(3) Catalytic Degradation of Eosin Dye. The catalytic activity of the biosynthesized copper nanoparticles was investigated against the water containing eosin dye. The kinetic reaction was observed using the UV-Visible spectrophotometer technique in the wavelength of $300-800 \mathrm{~nm}$. Figure 11 shows that the maximum peak value was obtained in the range of $500-515 \mathrm{~nm}$. As per the previous study, it also reported that the absorption spectrum of eosin was recorded at $517 \mathrm{~nm}$ [27]. Gradually, the peak disappears when the reaction time increases. Therefore, it indicates that eosin dye has been degraded in the existence of copper nanoparticles, as depicted in the figure.

\section{Conclusions}

Phytomediated synthesis of copper nanoparticles is a simple and ecofriendly method. In this study, plant leaf powder was used to prepare aqueous extract which was mixed with copper sulphate solution. The extract was reduced to copper sulphate and into copper nanoparticles. Synthesized copper nanoparticles were characterized by positioning of SPR band confirmed using UV-Vis Spectra. The crystalline structure and morphological characters were identified using XRD and SEM analysis. AFM image shows that topography characters of green-synthesized copper nanoparticles. The functional groups involved in the reduction of copper sulphate to copper nanoparticles were characterized by FTIR spectrum analysis. Hence, the synthesized nanoparticle was studied for medical applications such as antibacterial and antioxidant activity against pathogenic microorganisms and DPPH free radical. Other than that, the synthesized nanoparticle was utilized in environmental applications such as the toxic dye degradation process.

\section{Data Availability}

The data used to support the findings of this study are included within the article.

\section{Conflicts of Interest}

The authors declare no conflicts of interest.

\section{Authors' Contributions}

SR designed the study, and SR and MV carried out research, and SR, MV, and KA wrote and corrected the manuscript.

\section{References}

[1] A. Ahmad, S. Senapati, M. I. Khan, R. Kumar, and M. Sastry, "Extracellular biosynthesis of monodisperse gold nanoparticles by a novel extremophilic actinomycete, thermomonospora sp," Langmuir, vol. 19, no. 8, pp. 3550-3553, 2003.

[2] G. Singaravelu, J. S. Arockiamary, V. G. Kumar, and K. Govindaraju, "A novel extracellular synthesis of monodisperse gold nanoparticles using marine alga," Colloids and Surfaces B: Biointerfaces, vol. 57, no. 1, pp. 97-101, 2007.

[3] S. Rajeshkumar, C. Malarkodi, M. Vanaja, and G. Annadurai, "Anticancer and enhanced antimicrobial activity of biosynthesized silver nanoparticles against clinical pathogens," Journal of Molecular Structure, vol. 1116, pp. 165-173, 2016.

[4] M. Vanaja, S. Rajeshkumar, K. Paulkumar et al., "Fungal assisted intracellular and enzyme based synthesis of silver nanoparticles and its bactericidal efficiency," International Research Journal of Pharmaceutical and Biosciences, vol. 2, no. 3, pp. 08-19, 2015.

[5] S. Rajeshkumar, C. Malarkodi, K. Paulkumar, M. Vanaja, G. Gnanajobitha, and G. Annadurai, "Algae mediated green fabrication of silver nanoparticles and examination of its antifungal activity against clinical pathogens," International Journal of Metals, vol. 2014, p. 8, Article ID 692643, 2014.

[6] M. Vanaja and G. Annadurai, "Coleus aromaticus leaf extract mediated synthesis of silver nanoparticles and its bactericidal activity," Applied Nanoscience, vol. 3, no. 3, pp. 217-223, 2013.

[7] V. Parashar, R. Parashar, B. Sharma, and A. C. Pandey, "Parthenium leaf extract mediated synthesis of silver nanoparticles: a novel approach towards weed utilization," Digest Journal of Nanomaterials and Biostructures, vol. 4, no. 1, pp. 45-50, 2009.

[8] K. Paulkumar, G. Gnanajobitha, M. Vanaja et al., "Piper nigrum leaf and stem assisted green synthesis of silver nanoparticles and evaluation of its antibacterial activity against agricultural plant pathogens," Science World Journal, vol. 2014, p. 9, Article ID 829894, 2014.

[9] S. Rajeshkumar and G. Rinitha, "Nanostructural characterization of antimicrobial and antioxidant copper nanoparticles synthesized using novel Persea americana seeds," Open, vol. 3, pp. 18-27, 2018.

[10] A. Scott, K. P. Vadalasetty, A. Chwalibog, and E. Sawosz, "Copper nanoparticles as an alternative feed additive in poultry diet: a review," Nanotechnology Reviews, vol. 7, no. 1, pp. 69-93, 2018.

[11] V. L. S. Mulukuri, N. B. Mondal, M. R. Prasad, S. Renuka, and K. Ramakrishna, "Isolation of diterpenoid lactones from the leaves of Andrographis paniculata and its anticancer activity," International Journal of Pharmacognosy and Phytochemical Research, vol. 3, no. 3, pp. 39-42, 2011.

[12] M. Sivananthan and M. Elamaran, "Medicinal and pharmacological properties of Andrographis paniculata," International Journal of Biomolecules and Biomedicine, vol. 3, no. 2, pp. 1-12, 2013.

[13] M. Sharma and S. Joshi, "Comparison of antioxidant activity of Andrographis paniculata and Tinospora cordifolia leaves," Journal of Current Chemical and Pharmaceutical Science, vol. 1, no. 1, pp. 1-8, 2011. 
[14] C. S. Kalaivani, S. S. Sathish, N. Janakiraman, and M. Johnson, "GC-MS studies on Andrographis paniculata (Burm.f), Wall. ex Nees-a medicinally important plant," International Journal of Medicinal and Aromatic Plants, vol. 2, no. 1, pp. 69-74, 2012.

[15] R. Nagalekshmi, A. Menon, D. K. Chandrasekharan, and C. K. K. Nair, "Hepatoprotective activity of Andrographis paniculata and Swertia chirayita," Food and Chemical Toxicology, vol. 49, no. 12, pp. 3367-3373, 2011.

[16] P. Radhika and K. R. Lakshmi, "Antimicrobial activity of the chloroform extracts of the root and the stem of Andrographis paniculata nees," International Research Journal of Microbiology, vol. 1, no. 2, pp. 37-39, 2010.

[17] A. Nugroho, N. Warditiani, S. Pramono, M. Andrie, E. Siswanto, and E. Lukitaningsih, "Antidiabetic and antihiperlipidemic effect of Andrographis paniculata (Burm. f.) Nees and andrographolide in high-fructose-fat-fed rats," Indian Journal of Pharmacology, vol. 44, no. 3, pp. 377-381, 2012.

[18] J. Sattayasai, S. Srisuwan, T. Arkaravichien, and C. Aromdee, "Effects of andrographolide on sexual functions, vascular reactivity and serum testosterone level in rodents," Food and Chemical Toxicology, vol. 48, no. 7, pp. 1934-1938, 2010.

[19] V. K. Dua, V. P. Ojha, R. Roy et al., "Anti-malarial activity of some xanthones isolated from the roots of Andrographis paniculata," Journal of Ethnopharmacology, vol. 95, no. 2-3, pp. 247-251, 2004.

[20] M. Vanaja, K. Paulkumar, M. Baburaja et al., "Degradation of methylene blue using biologically," Bioinorganic Chemistry and Applications, vol. 20148 pages, 2014.

[21] N. Nagar and V. Devra, "Green synthesis and characterization of copper nanoparticles using Azadirachta indica leaves," Materials Chemistry and Physics, vol. 213, pp. 44-51, 2018.

[22] K. M. Rajesh, B. Ajitha, Y. A. K. Reddy, Y. Suneetha, and P. S. Reddy, "Optik Assisted green synthesis of copper nanoparticles using Syzygium aromaticum bud extract: physical, optical and antimicrobial properties," Optik, vol. 154, pp. 593-600, 2018.

[23] K. R. Reddy, "Green synthesis, morphological and optical studies of $\mathrm{CuO}$ nanoparticles," Journal of Molecular Structure, vol. 1150, pp. 553-557, 2017.

[24] A. Y. Ghidan, T. M. Al-Antary, and A. M. Awwad, "Green synthesis of copper oxide nanoparticles using Punica granatum peels extract: effect on green peach Aphid," Environmental Nanotechnology, Monitoring \& Management, vol. 6, pp. 95-98, 2016.

[25] D. Rehana, D. Mahendiran, R. S. Kumar, and A. K. Rahiman, "Evaluation of antioxidant and anticancer activity of copper oxide nanoparticles synthesized using medicinally important plant extracts," Biomedicine \& Pharmacotherapy, vol. 89, pp. 1067-1077, 2017.

[26] K. Jyoti and A. Singh, "Green synthesis of nanostructured silver particles and their catalytic application in dye degradation," Journal of Genetic Engineering and Biotechnology, vol. 14, no. 2, pp. 311-317, 2016.

[27] N. K. Mogha, S. Gosain, and D. T. Masram, "Gold nanoworms immobilized graphene oxide polymer brush nanohybrid for catalytic degradation studies of organic dyes," Applied Surface Science, vol. 396, pp. 1427-1434, 2017. 